\title{
Quantitative Measurement of Inferior Patellar Mobility: Sex-based Differences and Relationship With the Restricted Knee Flexion Angle Due to Aging
}

Hiroshi Ohko ( $\sim$ ohko-h@seijoh-u.ac.jp )

Seijoh University

\section{Susumu Ota}

Seijoh University

\section{Research Article}

Keywords: inferior patellar mobility, knee flexion angle, patellofemoral arthrometer, patellar displacement, reliability

Posted Date: March 2nd, 2022

DOl: https://doi.org/10.21203/rs.3.rs-1400894/v1

License: (c) (i) This work is licensed under a Creative Commons Attribution 4.0 International License.

Read Full License 


\section{Abstract}

Objective: To develop quantitative inferior patellar mobility (IPM) measurement methods and clarify the relationship between IPM and the knee flexion angle in community-dwelling elderly women.

Design: The study was performed from May 2015 to December 2017. The reference value and sex difference of IPM were evaluated in 205 healthy young adults (age: 19-21 years). Additionally, 128 healthy elderly women (age: 65-79 years) were recruited from the community to evaluate the relationship between IPM and knee flexion angle. IPMs was also compared between healthy elderly women and healthy young women. IPMs were measured objectively by using our specially designed patellofemoral arthrometer (PFA); patellar mobility was calculated by normalizing to body height. IPM reliability assessment was performed prior to all measurements.

Results: The intraclass correlation coefficients for intratester and intertester reliabilities varied from 0.87 to 0.99 . The normal range, based on 2 standard deviations, of inferior patellar displacement/body height was $5.9 \%-13.5 \%$ (young men), $5.1 \%-14.3 \%$ (young women), and $1.2 \%-8.8 \%$ (elderly women). The IPM was significantly lower in elderly women than in young women $(P<0.001)$. There was a significant positive correlation $(r=0.72, P<0.01)$ between IPM and the knee flexion angle in healthy elderly women who were unable to fully flex the knee joint.

Conclusions: Our PFA has good intratester and intertester reliability. The results suggest that IPM decreases with aging in women. IPM and the knee flexion angle are correlated among elderly women who are unable to fully flex the knee joint.

\section{Introduction}

The decrease in the range of motion (ROM) of the knee joint directly affects activities of daily living such as walking, using stairs, rising from a chair, and wearing or removing undergarments; therefore, it is important to maintain and improve $\mathrm{ROM}^{1-3}$. The decrease in the ROM of the knee flexion is associated with osteoarthritis ${ }^{4}$, stiffness after total knee arthroplasty $(T K A)^{5,6}$, postoperative arthrofibrosis ${ }^{7}$, and other complications. Moreover, bed rest ${ }^{8}$, shortening of the rectus femoris muscle ${ }^{9}$, and soft tissue changes ${ }^{10}$ such as adhesion around can occur as a result of or in tandem with underlying conditions.

According to Panni et $\mathrm{al}^{11}$. and Dragoo et al ${ }^{12}$, reduced patella mobility, especially in the inferior patella mobility, is associated with limited knee flexion ${ }^{11,12}$. Additionally, Jorosch et al. showed that the knee flexion angle could reportedly be improved in patients who undergo TKA by removing tissue adhesions around the patella (suprapatellar pouch, intra-articular fibrous bands, etc.) ${ }^{13}$. Although some reports claim that inferior patellar mobility is related to limited knee joint flexion ${ }^{14-16}$, such mobility has only been measured subjectively to date owing to the absence of a quantitative measurement method. The patellar gliding test, conducted by manually moving the patella in the medial and lateral, and inferior direction to end range of movement, is commonly used to measure passive patellar mobility ${ }^{17}$. The 
Cincinnati Knee Rating System and Kolowich (quadrant) method, which measure patellar mobility using the patellar sliding test, provide a subjective assessment of patellar movement ${ }^{18-20}$.

Ota et al. developed the patellofemoral arthrometer (PFA), which enabled reliable quantitative measurements of medial and lateral patellar mobility ${ }^{21,22}$. They used the PFA to investigate the knee flexion angle and medial and lateral (but not inferior) patellar mobility of patients post-TKA and found that these parameters were not horizontally related ${ }^{23}$.

Despite the aforementioned studies, the relationship between inferior patellar mobility and knee flexion angle remains relatively unexplored; to date, no quantitative method has been established for determining the former. Establishing such a quantitative evaluation method will help determine if a relationship exists between inferior patellar mobility and knee flexion angle; if so, this would validate the notion that improving inferior patellar mobility may be a therapeutic approach to improving knee joint flexion. Thus, this study was conducted to show that the knee flexion angle of elderly women with limited knee flexion was associated with decreased inferior patellar mobility. The healthy elderly recruited in this study were women with a high prevalence of knee osteoarthritis, who were expected to have reduced knee flexion angles.

The purpose of this study was as follows. (1) Reliability of inferior patellar mobility was confirmed using PFA in young healthy subjects. (2) Sex differences in inferior patellar mobility in young healthy subjects were confirmed. (3) Age-related changes in inferior patellar mobility in young healthy subjects and healthy elderly women were examined. (4) The relationship between inferior patellar mobility and knee joint flexion angle in healthy elderly women was examined.

\section{Methods}

\section{Subjects}

A total of 205 pain-free students from the Department of Rehabilitation and Care at Seijoh University, Japan, volunteered for the study (Table 1). Similarly, healthy women aged 65 years or older $(n=128)$ were recruited from the local community (Table 1). For each participant, we randomly chose the right or left patella by flipping a coin and then assessed its mobility. All participants were informed of the nature of the study before providing written informed consent; the study was approved by the Ethics Committees of Seijoh University (2013C0023). Exclusion criteria were having a history of knee pathology and/or testing positive on the clinical patellar test (such as Clarke's test or the patellar femoral grinding test).

\section{Assessment of patellar mobility}

Instrumentation: To assess inferior patellar mobility, a modified PFA with added superior and inferior patellar measurements (Brace Fit Co., Ltd., Aichi, Japan) was used with a digital caliper (Fig. 1). The PFA was designed to measure patellar displacement during the initial (fixed) frontal plane motion (medial, lateral, superior and inferior translation) in millimeters. 
Procedures: Data from the previous study were used to determine the evaluation posture of the subjects (i.e., $0^{\circ}$ hip rotation, supine position $)^{22,23}$. The PFA was clamped to the femoral condyles and firmly secured parallel to the bed by fastening it to the thigh with a strap. The digital caliper was positioned parallel to an imaginary line connecting the medial patella to the anterior superior iliac spine (Fig. 2). Before each test, the level of pushing force $(\sim 80 \mathrm{~N})$ was confirmed with a handheld MicroFET2 dynamometer (Hoggan Health Industries Inc., West Jordan, UT, USA). During the assessment, leg muscle relaxation was confirmed by palpating the quadriceps and passively moving the patella in the medial and lateral directions.

A pilot study was performed in which the patellar displacement was measured in 20 subjects (10 men and 10 women). There were significant differences in inferior patellar mobility on the third and subsequent measurements, and stable values were obtained (first vs. second: $P=0.01$, second vs. third: $P=0.04$, and third vs. fourth: $P=1.0$ ). Thus, the measurement was performed after mobility training had been conducted at least three times.

To measure inferior patellar mobility, the patellar apex was palpated and located with a laser by using the adjustable laser module arm, at which point the digital caliper was set to zero (i.e., the initial position) (Fig. 3A). The inferior displacement of the patella was then determined by manually pushing the patella inferiorly (at $80 \mathrm{~N}$ ), at which point that patellar apex was again located by sliding the laser module arm on the caliper and reading the measurement (Fig. 3B). Inferior patellar mobility was performed three times, and the average value was used for statistical analysis. Because displacement is thought to be affected by body size, the degree of displacement was normalized to body size as represented by height $(\mathrm{HT})^{24}$. Patellar mobility was adjusted for HT (patellar mobility/HT $\times 100$ ). The absolute values of inferior patellar displacement (IPD) and IPD/HT were used to compare patellar mobility between young men, young women, and elderly women.

\section{Reliability study}

Twenty-nine young pain-free individuals (15 men and 14 women) participated in the reliability study of IPD. The average age, $\mathrm{HT}$, and body mass index of the participants ( \pm standard deviation [SD]) were 21.5 \pm 0.6 years (men, $21.7 \pm 0.6$ years; women, $21.4 \pm 0.5$ years), $166.5 \pm 5.2 \mathrm{~cm}$ (men, $173.5 \pm 5.3 \mathrm{~cm}$; women, $159.5 \pm 5.2 \mathrm{~cm}$ ), and $21.5 \pm 0.6 \mathrm{~kg} / \mathrm{m}^{2}$ (men, $22.1 \pm 1.7 \mathrm{~kg} / \mathrm{m}^{2}$; women, $19.9 \pm 1.7 \mathrm{~kg} / \mathrm{m}^{2}$ ), respectively. Intra- and intertester reliability when quantifying inferior patellar mobility were determined based on measurements made by two different testers on different days.

Before data collection, testers 1 and 2 practiced measurements on 10 participants for $100 \mathrm{~min}$. They then randomly measured patellar mobility in the same session in each subject. Tester 1 performed the measurements in both testing sessions, which were at least three days apart for intratester reliability. Tester 2 assessed the patellar mobility on day 1 only to determine intertester reliability. The testers were blinded to all measurements. 
The intra- and intertester reliability of IPD readings obtained with the PFA were assessed by using intraclass correlation (ICC). The standard error of the mean (SEM) was calculated by using the following equation: $\mathrm{SEM}=\mathrm{SD} \times(\sqrt{ } 1-\mathrm{ICC})$. After the reliability study, the patellar mobility study commenced using the same procedures as in the practice session and reliability study. To further investigate the real patellar displacement beyond measurement errors, the smallest real difference (SRD) was used to indicate the magnitude of change that would exceed the expected trial-to-trial variability. The SRD was calculated by using the following equation: $1.96 \times \sqrt{2} \times \mathrm{SEM}^{25}$. The ICC, SEM, and SRD values are presented in Table 2 .

\section{Data analysis}

The Shapiro-Wilk test was used to test for normality. Unpaired $t$-tests were used to compare patellar mobility between young men and women as well as between young and elderly women. For comparisons between the three groups, a one-way analysis of variance was performed with the Tukey Kramer post-hoc method also used. Significance was set at $P<0.05$.

Healthy elderly women were classified into two groups based on whether or not they were able to sit in seiza (a Japanese style of kneeling with the buttocks resting on the turned-out heels); 92 women were able to fully flex the knee joint (the seiza-possible group), and 36 were unable to do so $\left(<150^{\circ}\right)$ (the seizaimpossible group). In each group, the correlation between patellar mobility and knee flexion angle was assessed by using Pearson's correlation coefficient. All statistical analyses were performed using SPSS, version 25.0 (IBM Corp., Tokyo, Japan).

\section{Results}

The intratester reliability in terms of IPD measurements was 0.99 ( $95 \%$ confidence interval [Cl]: 0.980.99 ) with an SEM of $0.29 \mathrm{~mm}$, while the SRD was $0.80 \mathrm{~mm}$. Intertester reliability in terms of IPD measurements was 0.87 (95\% Cl: 0.73-0.94); the SEM and SRD were $1.12 \mathrm{~mm}$ and $3.14 \mathrm{~mm}$, respectively (Table 2). Table 3 shows the absolute values of the IPD measurements in young men (IPD: $16.5 \pm 3.3 \mathrm{~mm}$, IPD/HT: $9.7 \pm 1.9 \%$ ) and women (IPD: $15.4 \pm 3.7 \mathrm{~mm}$, IPD/HT: $9.7 \pm 2.3 \%$ ) as well as in elderly women (IPD: $7.5 \pm 2.8 \mathrm{~mm}$, IPD/HT: $5.0 \pm 1.9 \%$ ); IPD/HT values normalized for body height are also shown. A significant difference was found in IPD between young men and women $(P=0.02,95 \% \mathrm{Cl}$ : $0.17-2.11)$. However, the normalized IPD (IPD/HT) did not differ significantly between the sexes $(P=0.85,95 \% \mathrm{Cl}$ : $-0.64-0.53)$. Thus, only the absolute displacement showed sex-based differences in IPD.

We defined the normal patellar mobility range as 2 SD within a specific group. In our sample, the normal IPDs in young men and women were 9.9-23.1 mm and 8.0-22.8 mm, respectively. Using the same definition, the normal IPD/HT ranges were $5.9-13.5 \%$ in young men and $5.1-14.3 \%$ in young women. Similarly, the IPD range among elderly women was $1.9-13.1 \mathrm{~mm}$, while the IPD/HT range was $1.2-8.8 \%$.

Absolute and corrected values for IPD were significantly lower in the seiza-possible group $(7.8 \pm 2.6 \mathrm{~mm}$, $5.2 \pm 1.7 \%)$ and seiza-impossible group $(6.7 \pm 3.3 \mathrm{~mm}, 4.5 \pm 2.2 \%)$ than in young women $(15.4 \pm 3.7 \mathrm{~mm}$, $9.7 \pm 2.3 \%)(P<0.001)$ (Table 4). 
Furthermore, the inferior patellar mobility in the seiza-impossible was significantly lower than that in both young women and the seiza-possible group in both adjusted and unadjusted models $(P=0.044)$. Additionally, there was a significant positive correlation $(r=0.72, P<0.001)$ in both adjusted and unadjusted models between inferior patellar mobility and the knee flexion angle in the seiza-impossible group (Fig. 4).

\section{Discussion}

The newly developed modified PFA with inferior patellar measurement can measure the inferior patellar mobility with good intra- and inter-examiner reliability (ICC, 0.87-0.99) and is suitable for clinical application. The main findings in this study are as follows. There was a significant difference in the absolute value of IPD between young men and women, but when adjusted for body height, the significant difference disappeared. Absolute and normalized values for IPD were significantly lower in elderly women than in young women. In addition, the seiza-impossible group of the elderly had significantly lower IPD than the seiza-possible group and young women. Additionally, in the seiza-impossible group of the elderly, there were significant positive correlations between the absolute and normalized values for IPD and the knee flexion angle.

Methods for evaluating the patella include tracking ${ }^{26}$, magnetic resonance imaging (MRI), computed tomography, conventional radiography in the static position ${ }^{27-30}$, and medial and lateral mobility assessment ${ }^{21-24}$. However, our method is a non-invasive method for dynamic evaluation of inferior patella mobility. It has been shown that the decrease in inferior patellar mobility is related to limited knee joint flexion ${ }^{31}$. To date, however, the inferior patellar mobility has been measured using subjective measurements of patellar flexibility [The Cincinnati Knee Rating System and Kolowich (quadrant) method] ${ }^{17,19}$. Hence, we are the also demonstrate its relationship with knee flexion angle using objective measurements. Additionally, using the mean \pm 2 SDs ( $94.2 \%$ of normal distribution among men and $94.6 \%$ of that among women), it was necessary to establish the mean inferior patellar mobility in young men and women and adjust for normalized by body height, as described in the previous reports ${ }^{21}$.

The inferior patellar mobility values among both the seiza-possible and seiza-impossible groups of elderly women were significantly lower than that among young women, with both elderly groups showing half the mobility of their young counterparts. Diminished muscle flexibility and increased soft tissue stiffness due to aging have been demonstrated in humans ${ }^{32}$. In particular, decreased soft tissue and muscle flexibility near the base of patella and distal thigh may affect the inferior patella mobility ${ }^{11-13}$. The inferior patellar mobility was significantly lower in the seiza-impossible group than in the seizapossible group. Furthermore, there was a significant correlation between inferior patellar mobility and knee flexion angle in the seiza-impossible group, suggesting that inferior patellar mobility influenced knee flexion angle.

Suprapatellar pouch lesion is considered to be one of the causes of the inferior patellar mobility. As the patella and suprapatellar pouch are connected, and adhesion of these two components may cause pain, 
flexion contractures, and stiffness ${ }^{13,33}$, which may reduce patellar mobility. Kapandji also reported that, when knee flexion increases from 90 degrees to more than 135 degrees, the suprapatellar pouch becomes completely 'unpleated' (i.e., straight without creases) ${ }^{34}$. The function of the suprapatellar pouch during knee flexion has been reported to be anatomically important; hence, it is possible that the inferior patellar mobility may be caused by diminished flexibility of soft tissues around the knee, including the suprapatellar pouch ${ }^{11}$.

The relationship between the flexibility of soft tissues around the knee and inferior patellar mobility was described as playing a role in some diseases that cause limited knee joint flexion. In the case of knee osteoarthritis, it has recently been suggested that joint inflammation is not only confined in the articular cartilage of the knee but also affects the surrounding soft tissues, leading to peripatellar lesions and knee stiffness ${ }^{35}$. In patients with knee joint fibrosis, the signs and symptoms of arthrofibrosis include reduced patellar mobility, diminished knee ROM, tenderness around the knee, pain, and atrophy of the quadriceps. Inferior patellar mobility has been shown to be a factor affecting diminished knee flexion ROM ${ }^{36-40}$. Furthermore, in patients with knee joint fibrosis, lesions around the patella such as in the infrapatellar fat pad, pretibial recess, anterior interval, and suprapatellar pouch may arise ${ }^{41}$, affecting inferior patellar mobility.

However, the causative factors of inferior patellar mobility have not been clearly determined because of the lack of methods that objectively evaluate it. Moving forward, it is necessary to clarify the relationship between inferior patellar mobility and soft tissue flexibility around the knee in patients with limited knee flexion. If the limit of inferior patellar mobility are identified, improvements in such mobility using therapeutic interventions can lead to an increased knee flexion angle.

Our study has some limitations. First, the subject was a healthy group, and patellar mobility was not compared in the patient population. In future studies, it would be necessary to examine patellar mobility in patients with knee osteoarthritis. Second, we did not compare our results with those obtained using gold-standard procedures (i.e., MRI or X-ray fluoroscopy) for validation. Ota et al. evaluated the mobility of the medial and lateral patella with MRI using conventional PFA and obtained good results ${ }^{22}$. Moreover, the position of the patella at rest needs to be specifically examined, as it may be related to the inferior mobility of the patella. Specifically, it is necessary to evaluate the Insall-Salvati ratio using radiography 27 . Third, we did not quantify the force that pushes down the patella; rather, we used a dynamometer that we practiced pushing at $80 \mathrm{~N}$ prior to measurement. However, it was unclear whether the optimal force was applied to push the patella downward in actual measurements. To solve this problem, it is necessary to consider obtaining measurements while pressing back the patella in real-time using a sheet sensor, for example.

\section{Conclusion}

The PFA that we developed can measure inferior patellar mobility with good intra- and inter-examiner reliability. Our results suggested that inferior patellar mobility decreases with aging in women. The 
mobility of the inferior patella in unable Seiza was significantly lower in elderly women who were unable to sit in seiza. And the knee flexion angle and inferior patellar mobility were correlated among elderly women who were unable to sit in seiza.

\section{Abbreviations}

Cl: Confidence interval; HT: Height; ICC: Intraclass correlation; IPD: Inferior patellar displacement; MRI: Magnetic resonance imaging; PFA: Patellofemoral arthrometer; ROM: Range of motion; SD: Standard deviation; SEM: Standard error of the mean; SRD: Smallest real difference; TKA: Total knee arthroplasty.

\section{Declarations}

\section{Ethical Approval and Consent to participate}

All participants were informed of the nature of the study before providing written informed consent; the study was approved by the Ethics Committees of Seijoh University (2013C0023).

\section{Consent for publication}

'Not applicable'

\section{Funding}

There was no funding supporting this study.

\section{Authors' contributions}

All authors have made substantial contributions to all three of the following: (1) the conception and design of the study, or acquisition of data, or analysis and interpretation of data; (2) drafting the article or revising it critically for important intellectual content; and (3) final approval of the version to be submitted. All authors critically appraised the manuscript and agreed to the final submission.

\section{Acknowledgements}

'Not applicable'

\section{References}

1. Laubenthal KN, Smidt GL, Kettlekamp DB. A quantitative analysis of knee motion during activities of daily living. Phys Ther 1972;52:34-43. https://doi.org/10.1093/ptj/52.1.34

2. Bergström G, Aniansson A, Bjelle A, Grimby G, Lundgren-Lindquist B, Svanborg A. Functional consequences of joint impairment at age 79. Scand J Rehabil Med 1985;17:183-90. 
3. Odding E, Valkenburg HA, Algra D, Vandenouweland FA, Grobbee DE, Hofman A. The association of abnormalities on physical examination of the hip and knee with locomotor disability in the Rotterdam Study. Br J Rheumatol 1996;35:884-90. https://doi.org/10.1093/rheumatology/35.9.884

4. Nishimura A, Hasegawa M, Kato K, Yamada T, Uchida A, Sudo A. Risk factors for the incidence and progression of radiographic osteoarthritis of the knee among Japanese. Int Orthop 2011;35:839-43.

5. Scranton PE Jr. Management of knee pain and stiffness after total knee arthroplasty. J Arthroplasty 2001;16:428-35. https://doi.org/10.1054/arth.2001.22250

6. Yercan HS, Sugun TS, Bussiere C, Ait Si Selmi T, Davies A, Neyret P. Stiffness after total knee arthroplasty: prevalence, management and outcomes. Knee 2006;13:111-7. https://doi.org/10.1016/j.knee.2005.10.001

7. Ayers DC, Dennis DA, Johanson NA, Pellegrini VD Jr. Common complications of total knee arthroplasty. J Bone Joint Surg Am 1997;79:278-311.

8. Clavet $\mathrm{H}$, Hébert PC, Fergusson D, Doucette $\mathrm{S}$, Trudel G. Joint contracture following prolonged stay in the intensive care unit. CMAJ 2008;178:691-7. https://dx.doi.org/10.1503\%2Fcmaj.071056

9. Bellemans J, Steenwerckx A, Brabants K, Victor J, Lammens J, Fabry G. The Judet quadricepsplasty: a retrospective analysis of 16 cases. Acta Orthop Belg 1996;62:79-82.

10. Judet J, Judet H, Aouak D. Stiffness of the knee of joint origin. Chirurgie 1989;115:457-60.

11. Schiavone Panni A, Cerciello S, Vasso M, Tartarone M. Stiffness in total knee arthroplasty. J Orthop Traumatol 2009;10:111-8. https://doi.org/10.1007/s10195-009-0054-6

12. Dragoo JL, Abnousi F. Disorders of the suprapatellar pouch of the knee. Knee 2008;15:348-54. https://doi.org/10.1016/j.knee.2008.02.009

13. Jerosch J, Aldawoudy AM. Arthroscopic treatment of patients with moderate arthrofibrosis after total knee replacement. Knee Surg Sports Traumatol Arthrosc 2007;15:71-7. https://doi.org/10.1007/s00167-006-0099-5

14. Wilk KE, Davies GJ, Mangine RE, Malone TR. Patellofemoral disorders: a classification system and clinical guidelines for nonoperative rehabilitation. J Orthop Sports Phys Ther 1998;28:307-22. https://doi.org/10.2519/jospt.1998.28.5.307

15. Joshi RP, Heatley FW. Measurement of coronal plane patellar mobility in normal subjects. Knee Surg Sports Traumatol Arthrosc 2000;8:40-5. https://doi.org/10.1007/s001670050009

16. Fredericson M, Yoon K. Physical examination and patellofemoral pain syndrome. Am J Phys Med Rehabil 2006;85:234-43. https://doi.org/10.1097/01.phm.0000200390.67408.f0

17. Wilk KE, Davies GJ, Mangine RE, Malone TR. Patellofemoral disorders: a classification system and clinical guidelines for nonoperative rehabilitation. J Orthop Sports Phys Ther 1998;28:307-22.

18. Nissen CW, Cullen MC, Hewett TE, Noyes FR. Physical and arthroscopic examination techniques of the patellofemoral joint. J Orthop Sports Phys Ther 1998;28:277-85.

19. Kolowich PA, Paulos LE, Rosenberg TD, Farnsworth S. Lateral release of the patella: indications and contraindications. Am J Sports Med 1990;18:359-65. 
20. Nomura E, Inoue M, Kobayashi S. Generalized joint laxity and contralateral patellar hypermobility in unilateral recurrent patellar dislocators. Arthroscopy 2006;22:861-865.

http://dx.doi.org/10.1016/j.arthro.2006.04.090

21. Ota S, Ward SR, Chen YJ, Tsai YJ, Powers CM. Concurrent criterion-related validity and reliability of a clinical device used to assess lateral patellar displacement. J Orthop Sports Phys Ther 2006;36:64552. https://doi.org/10.2519/jospt.2006.2263

22. Ota S, Nakashima T, Morisaka A, Ida K, Kawamura M. Comparison of patellar mobility in female adults with and without patellofemoral pain. J Orthop Sports Phys Ther 2008;38:396-402. https://doi.org/10.2519/jospt.2008.2585

23. Ota S, Nakashima T, Morisaka A, Omachi T, Ida K, Kawamura M. Is latero-medial patellar mobility related to the range of motion of the knee joint after total knee arthroplasty? Man Ther 2010;15:5748. https://doi.org/10.1016/j.math.2010.06.009

24. Ota S, Ohko H. Sex differences in passive lateral and medial patellar mobility in healthy young adults. J Back Musculoskelet Rehabil 2017;31:127-32. https://doi.org/10.3233/BMR-169704

25. Beckerman H, Roebroeck ME, Lankhorst GJ, Becher JG, Bezemer PD, Verbeek AL. Smallest real difference, a link between reproducibility and responsiveness. Qual Life Res 2001;10:571-8. https://doi.org/10.1023/a:1013138911638

26. Tanaka MJ, Elias JJ, Williams AA, Demehri S, Cosgarea AJ. Characterization of patellar maltracking using dynamic kinematic CT imaging in patients with patellar instability. Knee Surg Sports Traumatol Arthrosc 2016;24:3634-41. https://doi.org/10.1007/s00167-016-4216-9

27. Insall J, Falvo KA, Wise DW. Chondromalacia patellae. A prospective study. J Bone Joint Surg Am. 1976;58:1-8.

28. Grelsamer RP, Newton PM, Staron RB. The medial-lateral position of the patella on routine magnetic resonance imaging: when is normal not normal? Arthroscopy 1998;14:23-8. https://doi.org/10.1016/s0749-8063(98)70116-1

29. Herrington L. The effect of corrective taping of the patella on patella position as defined by MRI. Res Sports Med 2006;14:215-23.

30. Mirza Tolouei F, Afshar A, Salarilak S, Sina A. CT patellar cortex tilt angle: a radiological method to measure patellar tilt. Iran J Radiol 2005;3:17-21.

31. Sweitzer BA, Cook C, Steadman JR, Hawkins RJ, Wyland DJ. The inter-rater reliability and diagnostic accuracy of patellar mobility tests in patients with anterior knee pain. Phys Sportsmed 2010;38:906. https://doi.org/10.3810/psm.2010.10.1813

32. 32. Buckwalter JA. Maintaining and Restoring Mobility in Middle and Old Age: The Importance of the Soft Tissues. Instr Course Lect. 1997; 46: 459-69.

33. Fitzsimmons SE, Vazquez EA, Bronson MJ. How to treat the stiff total knee arthroplasty?: a systematic review. Clin Orthop Relat Res 2010;468:1096-106. https://doi.org/10.1007/s11999-010$1230-y$ 
34. Kapandji IA. The physiology of the joints. Vol 2. Lower limb. Honore LH (translator). Churchill and Livingstone, Edinburgh 1970: 92-103.

35. Felson DT, Lawrence RC, Dieppe PA, Hirsch R, Helmick CG, Jordan JM, et al. Osteoarthritis: new insights. Part 1: the disease and its risk factors. Ann Intern Med 2000;133:635-46. https://doi.org/10.7326/0003-4819-133-8-200010170-00016

36. de Miguel malesdieta E, Cobo Ibáñez T, Usón Jaeger J, Bonilla Hernán G, Martín Mola E. Clinical and ultrasonographic findings related to knee pain in osteoarthritis. Osteoarthritis Cartilage 2006;14:5404. https://doi.org/10.1016/j.joca.2005.12.012

37. Eakin CL. Knee arthrofibrosis: prevention and management of a potentially devastating condition. Phys Sportsmed 2001;29:31-42. https://doi.org/10.3810/psm.2001.03.668

38. Millett PJ, Wickiewicz TL, Warren RF. Motion loss after ligament injuries to the knee. Part l: causes. Am J Sports Med 2001;29:664-75. https://doi.org/10.1177/03635465010290052401

39. Shelbourne KD, Patel DV. Treatment of limited motion after anterior cruciate ligament reconstruction. Knee Surg Sports Traumatol Arthrosc 1999;7:85-92. https://doi.org/10.1007/s001670050127

40. Shelbourne KD, Patel DV, Martini DJ. Classification and management of arthrofibrosis of the knee after anterior cruciate ligament reconstruction. Am J Sports Med 1996;24:857-62. https://doi.org/10.1177/036354659602400625

41. Enad JG. Arthroscopic lysis of adhesions for the stiff total knee arthroplasty. Arthrosc Tech 2014;3:e611-4. https://doi.org/10.1016/j.eats.2014.07.001

\section{Tables}

Tables 1 to 4 xlsx are available in the Supplemental Files section.

\section{Figures}




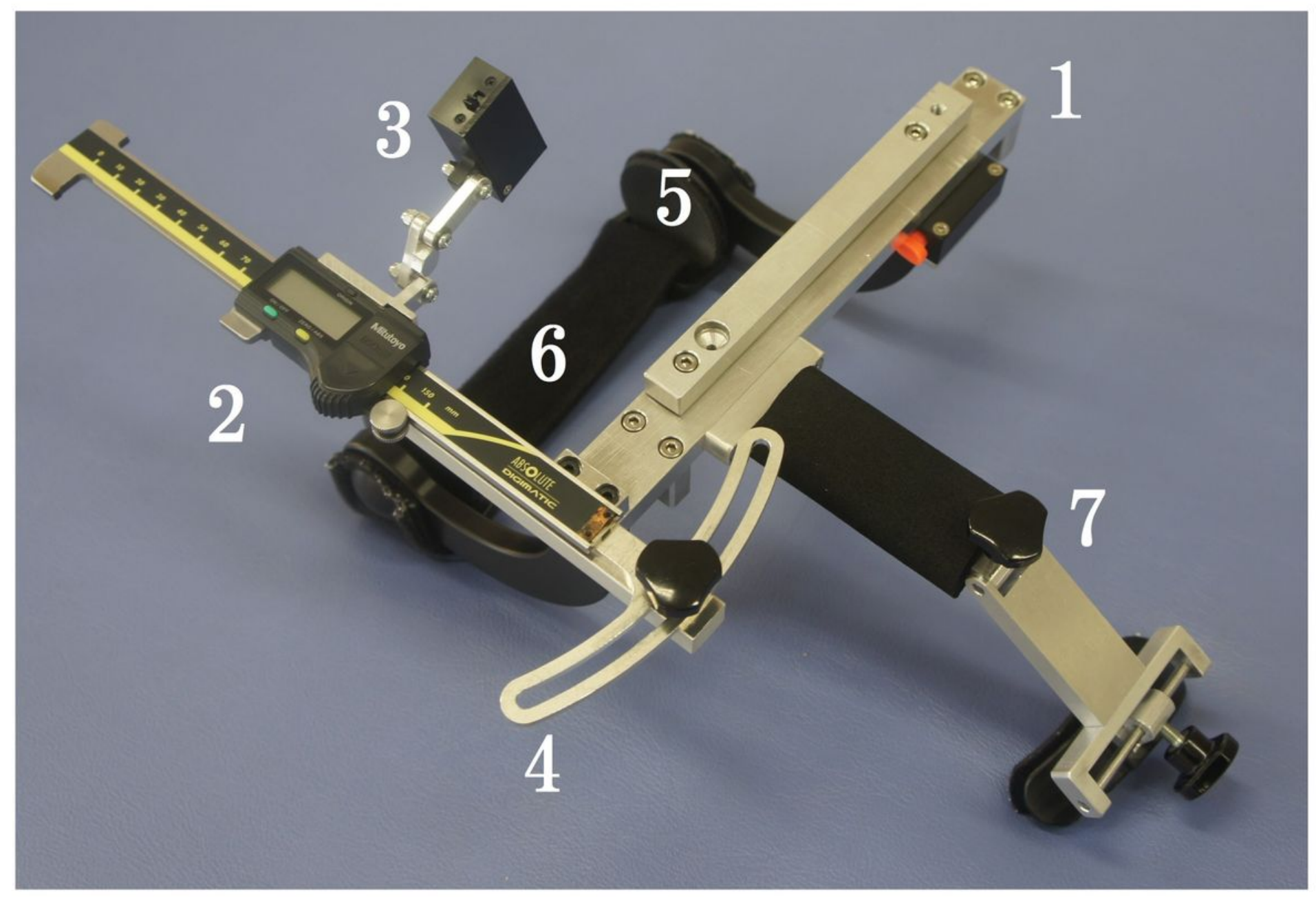

\section{Figure 1}

Components of the patellofemoral arthrometer. (1) base, (2) digital caliper, (3) adjustable laser module arm, (4) plane adjuster, (5) clamping mechanism, (6) thigh strap, and (7) fixed arm. 


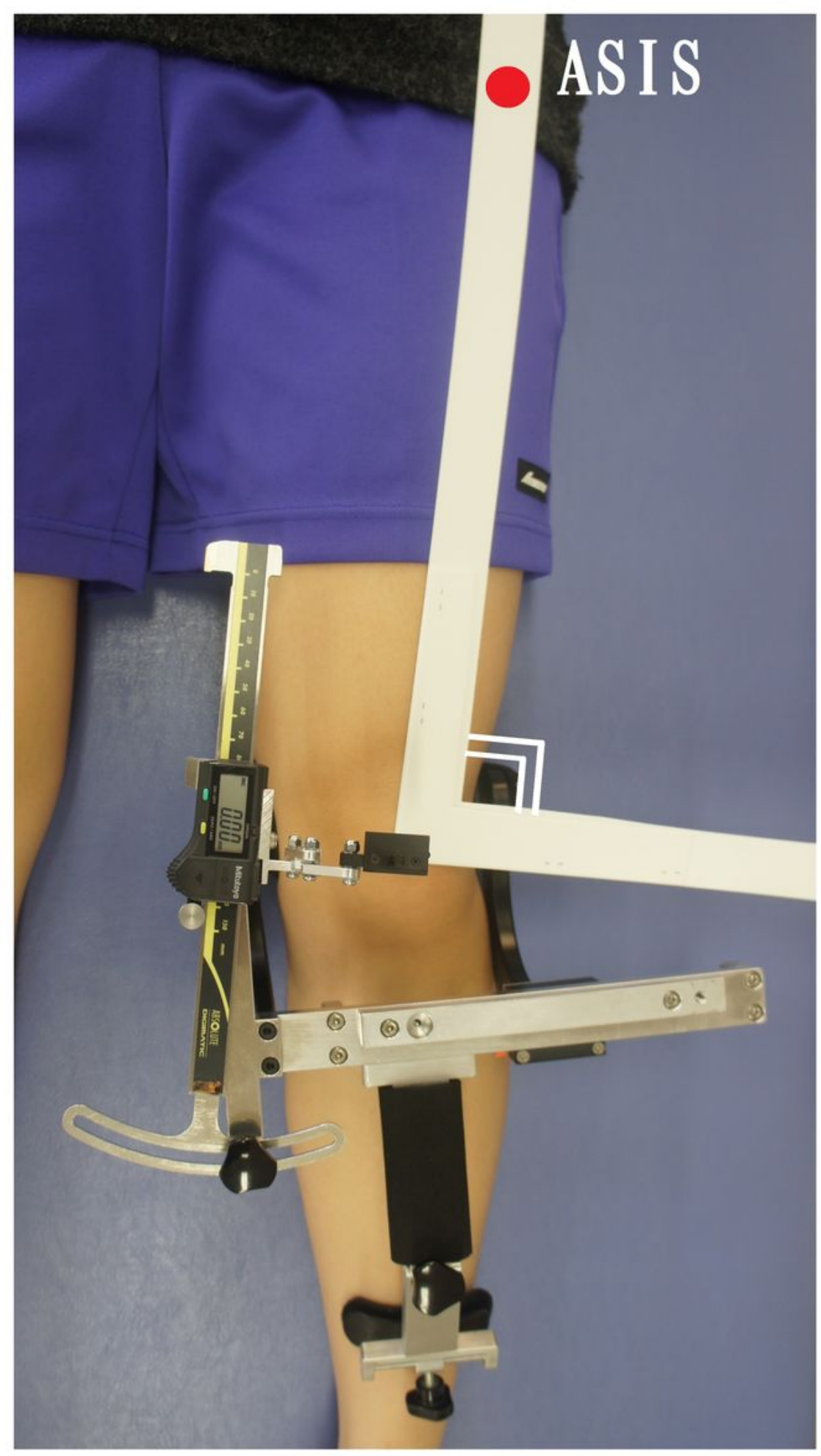

\section{Figure 2}

The patellofemoral arthrometer can be clamped to the femoral condyles. The plane adjuster allows the digital caliper to lie parallel to the imaginary line between the center of the patella and the anterior superior iliac spine (ASIS). 

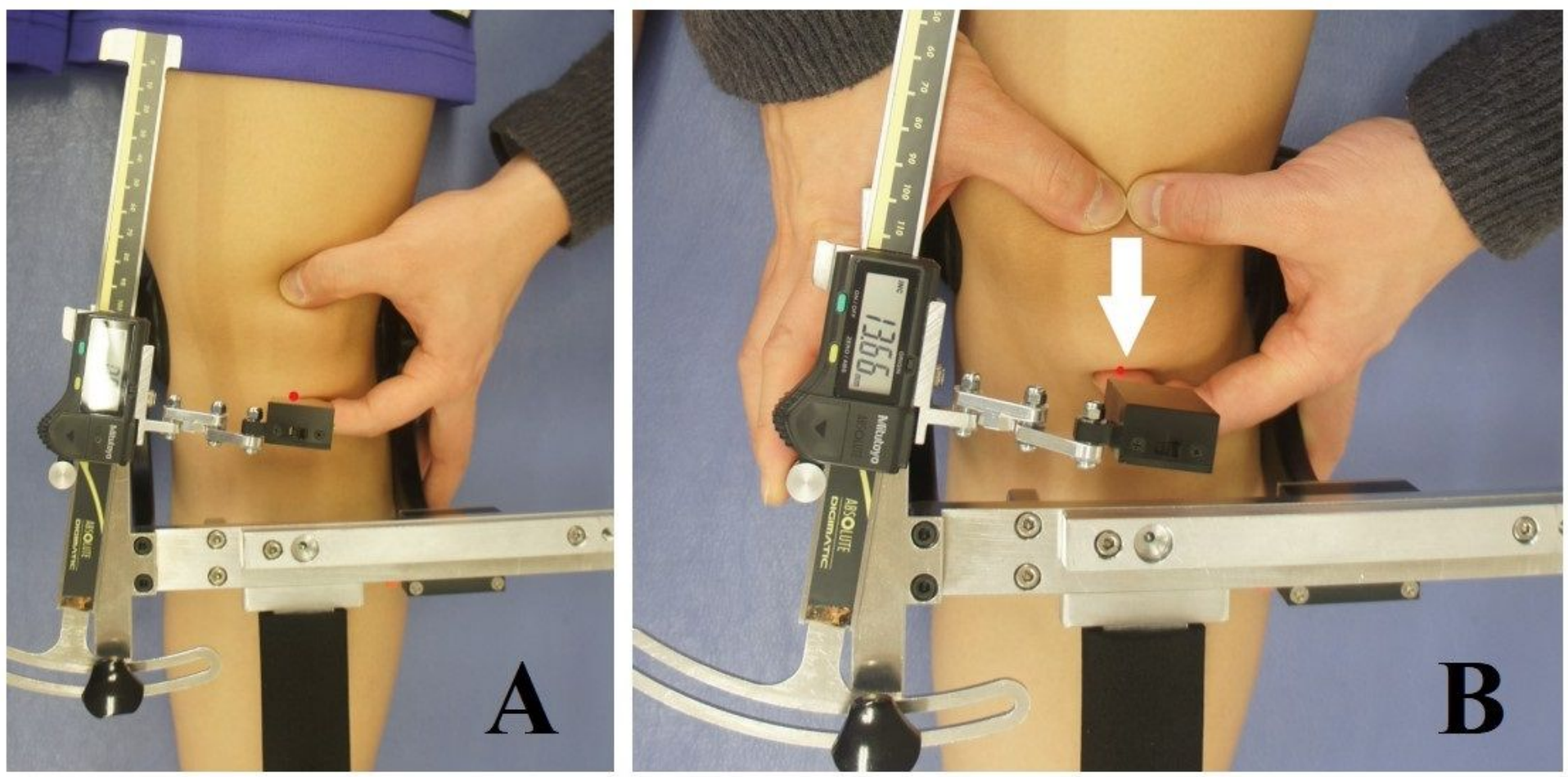

Figure 3

(3A) The patellar apex was located by palpation and aligned to the laser of the adjustable laser module arm. This was considered the initial position for patellar mobility measurements, with the digital caliper set to $0 \mathrm{~mm}$. (3B) Inferior patellar mobility was measured as the difference between the initial position (patellar apex) and the position following the application of an $80 \mathrm{~N}$ inferior force.
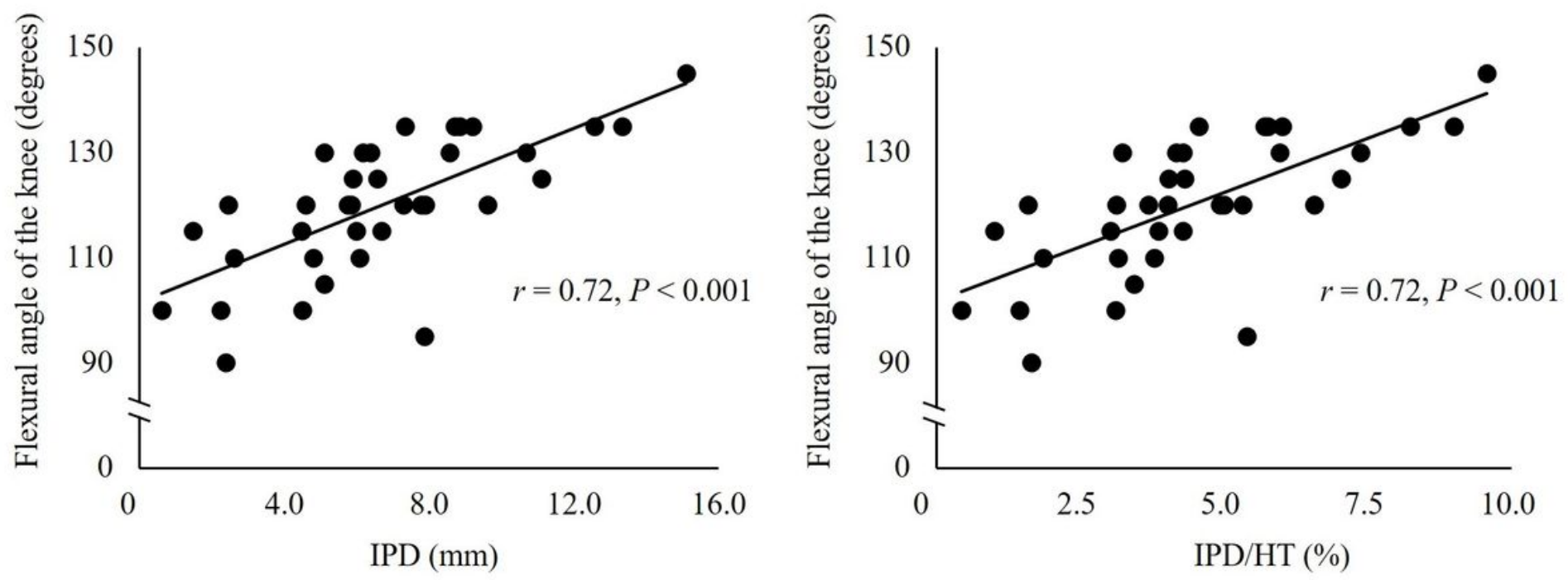

Figure 4

Relationship between inferior patellar mobility and knee flexion angle among elderly women who could not sit in the 'seiza' position. 
The correlations between patellar mobility and the knee flexion angle in the seiza possible and seiza impossible groups were assessed by using Pearson's correlation coefficient. Abbreviations: IPD, inferior patellar displacement; HT, height.

\section{Supplementary Files}

This is a list of supplementary files associated with this preprint. Click to download.

- Table1.xlsx

- Table2.xlsx

- Table3.xlsx

- Table4.xlsx 